\title{
Malignant chickenpox with coagulopathy in a healthy adult female; a case report and review of literature
}

\author{
De Vas Goonewardane APN, Sanjeewa NHR, Perera T, Weerakoon RR \\ Teaching Hospital, Karapitiya, Galle, Sri Lanka.
}

\author{
Correspondence: Dr.APNDe Vas Goonewardane \\ e-mail:nishanvas@yahoo.com
}

\begin{abstract}
Introduction
Varicella Zoster virus is a double stranded deoxyribonucleic acid virus of alphaherpesvirinae subfamily. It is the aetiological agent of usually self limiting primary disease commonly known as chickenpox in children and adolescents. Reactivation of dormant infection is known as herpes zoster ("Shingles"). Disseminated Varicella infection with organ dysfunction is sometimes rarely seen amongst diabetics and immunocompromised patients (1)

We present a case of presumably healthy adult female who acquired primary Varicella infection which progressed to malignant disease with lung, liver and haematological complications and then discuss the therapeutic options available.
\end{abstract}

\section{Case report}

A 60-year-old female presented with high fever, epigastric pain and vomiting for one day duration. Pain was severe and did not respond to analgesics including opioids. On admission patient was in pain, heart rate of $110 / \mathrm{min}$ with blood pressure 160/100 $\mathrm{mmHg}$. There were few bilateral coarse crepitations in lower zones of lungs with epigastric and right hypochondriac tenderness on abdominal examination. No evidence of hepatomegaly or peritonitis. She was conscious rational, without any features of encephalitis and cerebellar disease.

On second day of admission she developed classical blisters with "Dew-drop on Rose-petal" appearance. Vesicles started to spread from the chest and rapidly generalized with haemorrhagic transformation. Oral mucosa was also involved with palatal ulcers. Oral acyclovir was started at the first crop of blisters but she developed generalised abdominal pain with petechiae and ecchymoses of skin on the third day. Large spontaneous bruise marks were seen in limbs and simultaneously she started passing red coloured urine. Marked guarding and rigidity of abdomen were noted. Complete blood count showed lymphocytic leukocytosis with a total count of $24,000 / \mathrm{mm}^{3}$ with lymphocytes $54 \%$ and neutrophils $40 \%$ on differential count. Haemoglobin on admission was $12.1 \mathrm{~g} / \mathrm{dL}$ and reduced up to $7.1 \mathrm{~g} / \mathrm{dL}$ by third day. Platelets were initially $140,000 / \mathrm{mm}^{3}$ but rapidly reduced to $8000 / \mathrm{mm}^{3}$ with bleeding manifestations. Blood picture showed evidence of microangiopathic haemolysis with probable disseminated intravascular coagulation.

Prothrombin time was $20 \mathrm{sec}$ with an INR of 1.44, APTT 50 seconds and d-dimers were elevated. Liver profile showed elevated transaminases of SGPT; 2080U/L, SGOT; 4220U/L, total bilirubin; $2.15 \mathrm{mg} / \mathrm{dL}$, ALP; 665U/L. Ultrasound abdomen scan was normal. Chest radiograph showed features of bilateral Varicella pneumonia with evidence of bronchopneumonia. Saturation on high flow oxygen was $84 \%$. Arterial blood gas analysis revealed $\mathrm{pH}$; 7.01, $\mathrm{PO}_{2} ; 55 \mathrm{mmHg}, \mathrm{PCO}_{2} ; 50 \mathrm{mmHg}$ and $\mathrm{HCO}_{3}$; $11 \mathrm{mmol} / \mathrm{L}$. ECG showed sinus tachycardia and 2D-ECHO revealed no evidence of myocarditis or heart failure. Urine output was throughout adequate despite haematuria and serum creatinine was 0.5 $\mathrm{mg} / \mathrm{dL}$. Fasting blood glucose was $116 \mathrm{mg} / \mathrm{dL}$.

Patient was started on intravenous acyclovir and vancomycin according to the advice of microbiologist. Fluids and semi-solid food were administered through intravenous route and nasogastric tube, respectively because patient found oral intake excruciatingly painful. Septic screening with cultures was negative. Eight units of platelets and ten units of fresh frozen plasma were transfused 
for component correction. Patient was admitted to intensive care unit on the $3^{\text {rd }}$ day of admission for increasing dyspnoea, low blood pressure and multi organ failure, where she was intubated and ventilated. Acidosis was corrected and inotropes commenced. Despite intensive support she succumbed due to fulminant sepsis and organ failure on sixth day.

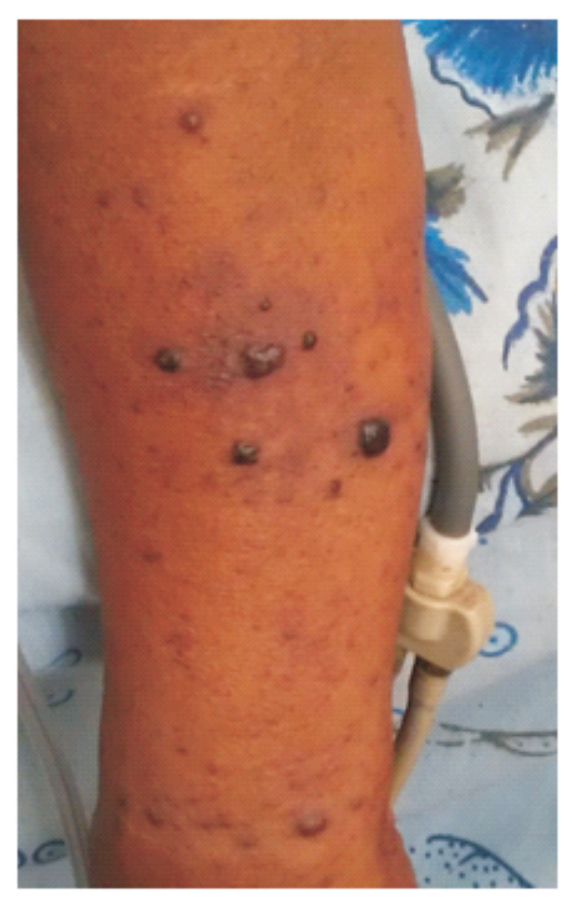

Figure 1: Haemorrhagic Varicella blisters of an arm day three

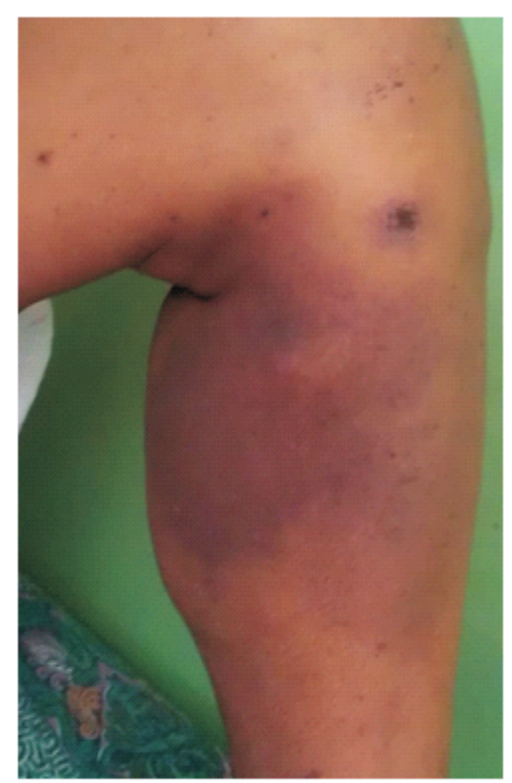

Figure 2: Large patch of ecchymoses with onset of coagulopathy
Disseminated haemorrhagic Varicella can cause Varicella pneumonia, encephalitis, hepatitis and haemorrhagic complications (2). People with blood or solid organ malignancy who are on immuno-suppresants, thrombophilics (protein $\mathrm{C}$ and $\mathrm{S}$ deficiencies) and diabetics are considered as susceptible groups $(1,3)$.

Haemorrhagic complications seen prominently in this patient, are described in five major clinical syndromes (4). Febrile purpura, malignant chickenpox with purpura, post-infection purpura, purpura fulminans and anaphylactoid purpura. Our patient fits second type criteria the best. Acyclovir is a guanosine nucleotide analogue and a selective inhibitor of herpes virus replication. Oral acyclovir and valacyclovir are considered for healthy adults at increased risk of fulminant Varicella. Acyclovir in a dose of $800 \mathrm{mg}$ five times a day for a week minimizes symptoms and disease duration. Lung and nervous system involvement is sometimes rarely seen in healthy individuals.

In contrast immuosuppresed patients benefit from intravenous acyclovir. Some of these patients turn out to be acyclovir resistant due to either resistant viral strain or host factors. Alternatives in this situation are brivudin, foscarnet, vidarabine and interferon (5). Prompt initiation of anti-viral treatment, being vigilant on herpes viral infections in immunocompromised patients and intensive care support are fundamental to success in managing fulminant chickenpox patients. Susceptible patients should take necessary precautions to prevent acquiring the disease at the first place.

\section{References}

1. Vinzio S, Lioure B, Goichot B. Varicella in immunocompromised patients. Lancet, 2006;368(9554): 2208.

2. Karadag AS, Bilgili SG, Calka O, et al. A case of fulminant varicella infection with purpura fulminans, hepatitis, and rhabdomyolysis. Indian J Dermatol, 2012; 57(6): 503.

3. Nguyen P, Reynaud J, Pouzol P, et al. Varicella and thrombotic complications associated with transient protein $\mathrm{C}$ and protein $\mathrm{S}$ deficiencies in children. Eur J Pediatr, 1994; 153(9): 646-9.

4. Maness D L, Rogers D Y. Haemorrhagic complications of varicella. Am Fam Physician, 1987; 35(2): 151-5.

5. Safrin S, Berger T G, Gilson I, et al. Foscarnet therapy in five patients with AIDS and acyclovir-resistant varicellazoster virus infection. Ann Intern Med, 1991; 115(1): 19-21. 